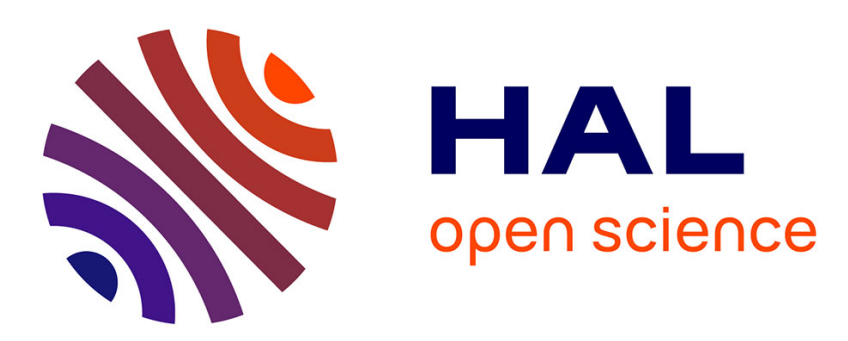

\title{
The Political Economy of Fixed Regional Public Expenditure Shares with an Illustration for Belgian Railway Investments
}

Stef Proost, Vera Zaporozhets

\section{- To cite this version:}

Stef Proost, Vera Zaporozhets. The Political Economy of Fixed Regional Public Expenditure Shares with an Illustration for Belgian Railway Investments. Regional Science and Urban Economics, 2013, 43 (5), pp.808-815. 10.1016/j.regsciurbeco.2013.08.001 . hal-02652018

\section{HAL Id: hal-02652018 \\ https://hal.inrae.fr/hal-02652018}

Submitted on 29 May 2020

HAL is a multi-disciplinary open access archive for the deposit and dissemination of scientific research documents, whether they are published or not. The documents may come from teaching and research institutions in France or abroad, or from public or private research centers.
L'archive ouverte pluridisciplinaire HAL, est destinée au dépôt et à la diffusion de documents scientifiques de niveau recherche, publiés ou non, émanant des établissements d'enseignement et de recherche français ou étrangers, des laboratoires publics ou privés. 


\title{
The Political Economy of Fixed Regional Public Expenditure Shares with an Illustration for Belgian Railway Investments*
}

\author{
Stef Proost ${ }^{\dagger} \quad$ Vera Zaporozhets ${ }^{\dagger}$
}

July 2013

\begin{abstract}
Many local public goods are allocated by federal governments using fixed regional shares: every region is entitled a fixed share of the total budget for a particular type of public good. This paper explores two characteristics of this type of allocation. First, it shows that this type of allocation is relatively efficient as it puts a strict budget constraint on the decisive region. Second, we show that these fixed shares can be an equilibrium of different legislative bargaining processes. The working of the fixed sharing rules is illustrated for the allocation of railway investments in Belgium.
\end{abstract}

Keywords: local public goods, political economy, railways

JEL codes: H41, H77, L98

*We thank the editor and two anonimous referees as well as B. De Borger and A. Glazer for helpful comments on a previous version of this paper, Evi Meire for excellent research assistance and EIBurs program for financial assistance.

${ }^{\dagger}$ University of Leuven, Faculty of Business and Economics, Naamse straat, 69, 3000 Leuven Belgium (Stef.Proost@econ.kuleuven.be).

$\ddagger$ Toulouse School of Economics (INRA-LERNA), Université des Sciences Sociales, 1 Rue des Amidonniers, 31000 Tououse, France, (vzaporoz@toulouse.infra.fr). 


\section{Introduction}

In this paper we analyze the allocation of public expenditures over regions in a federal state. In particular, we are interested in the role of the fixed sharing rule. By fixed sharing rule we mean that each region in a federation gets a fixed share of the total budget for a particular regional public good. A regional public good is a good that mainly benefits the region where it is supplied and the quantity supplied can differ among regions. The fixed sharing rule seems to be present in many federations. It is often based on a combination of population, GDP etc. Sometimes it is explicitly stated in a ruling or law, sometimes it is more like a tacit agreement. In the EU, the rule is often used to allocate investment money over member countries. It has been used explicitly in the UK to allocate public funds to the different regions - this was the so called Barnett formula introduced in 1978 (Bristow, 2001). It also appears in the international river agreements where the most common sharing rule is a "percentage" rule which assigns fixed shares of water flow to the participating countries (Beach et al. (2000)). It is used in Belgium to allocate federal investment funds to railway projects. It was the latter example that draw our attention and this example will be used to illustrate our theory. But there are many more examples where the allocation of public expenditures is approved after having made reference to one or another rule that is not based on an explicit benefit-cost analysis of the public expenditure.

Economists often consider such an allocation a very inefficient and senseless allocation as there is no explicit optimization of resources over regions. These considerations lead us to the three questions we address in this paper. First, we analyze under what conditions the fixed sharing rule allocation does not depart too far from the first-best, and how it differs from the uncoordinated common-pool allocation. Second, we discuss what mechanism determines the precise fixed sharing rules that are used in a federation. Third, we assess the working of fixed regional shares numerically for one case study: regional rail investments in Belgium.

To provide an answer to the first question, in sections 3 and 4 we present a political economy model with the regions as the main players, and consider the investments or expenditures as local public goods. We define three different allocation mechanisms for regional 
investments. The first-best will serve as a benchmark. The second allocation mechanism is the common-pool allocation, where every region can decide on its own investment level and where all investments have to be financed by federal tax revenues. The third alternative is the allocation of the total investment budget over the regions according to a fixed sharing rule. We show that, in general, the fixed sharing rule performs better than the common pool allocation, and we provide conditions under which the fixed sharing rule approximates the first best allocation. The main benefit of the fixed sharing rule equilibrium is that it imposes a strong budget constraint on the region that is decisive at the federal level: it can spend more in its own region but the fixed sharing rule implies it will have to spend (and pay) more in the other regions.

In section 5, we use two variants of a legislative bargaining model to study the determination of the fixed regional shares. In the first variant the share of each region is determined in a constitutional type of agreement approved unanimously or by a qualified majority. One of the main implications of this bargaining model is that, the stronger the region in terms of proposal power, the bigger is its share in the federal budget. In the second variant we show that the fixed shares can be an equilibrium in trigger strategies. This can be more considered as an implicit rule. We introduce the possibility to deter cheating on agreed shares, and show that under rather general conditions, reasonable fixed shares can be supported as an equilibrium. Both variants of the bargaining model give rise to the regional shares proportional to the bargaining power of the regions. Bargaining power of the regions is reflected by the probabilities of being selected as an agenda setter, and those are often proportional to the population size.

In section 6 , we illustrate the results and the welfare effects of the alternative regional allocations for rail investments in Belgium. Currently rail investment expenditures in Belgium are decided and paid by the federal government in agreement with the regions. It seems that no political agreement is possible if the rail investment expenditures do not follow a historical sharing rule of $60 \%$ for Flanders and $40 \%$ for the Walloon region. One of our main findings for this example is that, as such, the fixed 60/40 sharing rule for federal funds in Belgium does not necessarily generate large efficiency losses. 


\section{Related Literature}

One of the main concerns of public and political economists is the inefficiency of local public goods provision by a central legislature. Starting with Tullock (1959) and Weingast et al. (1981), economists have modelled fiscal policy in democratic regimes as a common pool problem and addressed the question of fiscal inefficiency in the form of excessive spending. The reason for this inefficiency is that the benefits are concentrated in specific jurisdictions while the costs are spread across all the jurisdictions.

More recent theoretical studies readdress this problem. For instance, Besley and Coate (2003) incorporate cross-regional spillovers in the model to study which level of government, central or local, should decide on the provision of the local public good.

The empirical issue of the common pool problem also has been tackled in a variety of studies. Among others, Knight (2004) proves existence of the common pool incentives by analyzing 1988 Congressional votes over transportation project funding. It is shown that the probability to gain support for a project by a legislator is increasing in the local spending and decreasing in contributions to the federal tax revenues. This result implies aggregate overspending, especially in politically powerful localities, as well as large deadweight losses.

As an alternative to a common pool allocation, federal governments can entitle each region to a fixed share of the total budget. Sometimes these fixed shares come from a proportional scheme: the public good is allocated in proportion to a single numerical criterion, such as population.

In order to explain the determinants of regional shares as an outcome of a political process, we employ the theoretical legislative bargaining model of Baron and Ferejohn (1989) with a modification: the probabilities of becoming an agenda-setter (or recognition probabilities) vary across the legislators. The most closely related paper in this sense is that of Knight (2005). However, in his work there are only two types of legislators with respect to the recognition probability: members vs. non-members of a transportation committee. Another difference with his paper is that we consider not only a standard infinite version of BaronFerejohn model but also an alternative variant, in which we introduce the possibility of 
punishment to deter deviations from the specified sharing rule.

It is worth to mention studies that, using an axiomatic perspective, provide conclusions similar to ours. Thus, Young et al. (1982) compare behavior of different allocation methods ${ }^{1}$ in practice on the basis of principles, which include simplicity and reasonable information requirements, in addition to certain "fairness" principles. One of the conclusions is that the simple scheme based on allocating costs in proportion to population may be preferable to more equitable approaches that are rather complicated and require detailed information, which is not always available.

To the best of our knowledge none of the studies addresses either the question of efficiency of fixed sharing rule or has considered such a rule as an alternative to the inefficient common pool allocation.

\section{The Model and Assumptions}

In this section we describe the setup and the main ingredients of the model. Following Persson (1998) we consider a federal state with $n \geq 2$ regions. Each region has a homogeneous population. The federal government uses federal tax revenue to provide a local public good in those regions.

The federal government uses a labor tax $t$ to finance the provision of the public good $g_{i}$ in region $i=1$..n. We denote by $L_{i}$ the total labor supply in region $i$ and assume that it is fixed. The total pool of tax revenues is then equal to $t \sum_{i=1}^{n} L_{i}$. Since labor supply is fixed, the labor tax does not cause any distortions in the labor market. We assume that the cost $c_{i}$ of providing one unit of the public good differs among the regions because of geographical characteristics, for instance.

The federal government budget constraint is:

$$
t \sum_{i=1}^{n} L_{i}=\sum_{i=1}^{n} c_{i} g_{i}
$$

\footnotetext{
${ }^{1}$ The general cost/surplus sharing problem has been extensively studied from an axiomatic perspective. A comprehensive survey of this strand of the litereature is provided in Young (1994) and Moulin (2002) among others.
} 
from which we can easily express $t$ as:

$$
t=\frac{\sum_{i=1}^{n} c_{i} g_{i}}{\sum_{i=1}^{n} L_{i}} .
$$

The preferences for each region $i$ with respect to the local public good $g_{i}$ and private consumption $q_{i}$ are represented by a quasi linear utility function:

$$
u_{i}=q_{i}+H_{i}\left(g_{i}\right), i=1 . . n .
$$

In line with the standard assumptions the function $H_{i}\left(g_{i}\right)$ is an increasing and concave benefit function that corresponds to the utility derived by region $i$ from expenditure $g_{i}$ on the public good:

$$
H_{i}(0)=0, H_{i}^{\prime}\left(g_{i}\right)>0 \text { and } H_{i}^{\prime \prime}\left(g_{i}\right)<0, i=1 . . n .
$$

We use Persson's approach as a starting point but assume specific benefit functions $H_{i}$ for each region, because it is possible that the local public good is used more intensively in some regions.

\section{Comparing Different Allocation Rules}

In this section we consider the properties of three alternative allocations. First, we consider the first-best situation where the federal government allocates the public good expenditures to the regions in order to maximize overall federal welfare. Next, we discuss the common-pool allocation. Finally, we analyze the results of the fixed regional sharing rule.

\subsection{The First-Best Benchmark}

In the first-best equilibrium and in a normative interpretation, a federal policy-maker maximizes a general social welfare function, subject to its budget constraint and having nondistortionary and individualized taxes at its disposal. If we assume that income distribution between the regions does not matter ${ }^{2}$, so that the social welfare function is the simple sum

\footnotetext{
${ }^{2}$ Alternatively, we could assume that the federal government has lump sum taxes and transfers and uses a Bergson-Samuelson social welfare function. This type of social welfare function can be the result of a
} 
of utilities, we can reach the first best with the non-distortive tax on the resources of the federation:

$$
\max _{g_{i}}\left[(1-t) \sum_{i=1}^{n} L_{i}+\sum_{i=1}^{n} H_{i}\left(g_{i}\right)\right]
$$

s. t. constraint (1).

After substituting for $t$ from (2) we derive the following first order conditions:

$$
\frac{d H_{i}\left(g_{i}^{F B}\right)}{d g_{i}}=c_{i}, \text { for } i=1 . . n
$$

where FB stands for the first-best allocation.

This standard result states that the marginal benefit from a unit of local public good investments is equal to its marginal cost.

Notice that the same result can be reached if we assume decentralized decisions: the regional governments have to decide on their own public good provision and pay for it with a local non-distortionary tax.

\subsection{The Non-cooperative Common Pool Solution}

In this subsection, we assume that each region proposes its preferred expenditures level, knowing that it has to be paid out of federal taxes. All regions act non-cooperatively. Now each region $i$ solves the following maximization problem (taking $g_{i}, j \neq i$ as given):

$$
\begin{aligned}
& \max _{g_{i}}\left[(1-t) L_{i}+H_{i}\left(g_{i}\right)\right] \\
& \text { s. t. constraint (1). }
\end{aligned}
$$

Again, after substitution for $t$ from (2), we obtain the preferred investment level for each region:

$$
\frac{d H_{i}\left(g_{i}^{C P}\right)}{d g_{i}}=\frac{c_{i} L_{i}}{\sum_{i=1}^{n} L_{i}}, \text { for } i=1 . . n
$$

bargaining process. This would result in another allocation of the numeraire good $c$ as the lump sum taxes and transfers would equalize the marginal social utility of income (derivative of welfare function with respect to the numeraire good). The use of the lump sum redistribution instruments would not affect the allocation of local public goods because with the quasi-linear utility function, the demand for public goods is independent of the income level. 
where CP stands for the common pool allocation. The level preferred in the common pool allocation is independent of the quantity selected by the other regions because there are no spillovers, all taxes are lump sum and there are no income effects for the demand for the local public good. One can notice that

$$
\frac{d H_{i}\left(g_{i}^{C P}\right)}{d g_{i}}<c_{i}=\frac{d H_{i}\left(g_{i}^{F B}\right)}{d g_{i}},
$$

i.e., now the marginal benefit of a unit of the public good is lower than the marginal cost, and therefore, the regions prefer an amount of public good that is larger than the first-best allocation. This implies a higher total expenditure for the public good and a higher tax level.

The over-consumption leads to a welfare loss compared to the first-best allocation.

\subsection{The Fixed Sharing Rule Allocation}

In this subsection we assume a fixed sharing rule: all public good expenditures are paid out of the federal budget according to the fixed shares $\alpha_{i}$ for each region $i$. We suppose that each $\alpha_{i} \in(0,1)$ and $\sum_{i=1}^{n} \alpha_{i}=1$.

The regional shares are fixed but the total volume of investments is still to be determined. In order to understand the efficiency effects of this type of allocation, we analyze two extreme assumptions: either the unweighted sum of regional welfares is maximized or there is one region that decides on the total budget, maximizing its own welfare.

We first assume that the federal government maximizes the unweighted sum of regional welfares under a regional fixed sharing constraint. It therefore decides on the total budget for local public good provision $G$, which is the sum of all the local public good expenditures, given its budget constraint and the fixed sharing rules for the regions: 


$$
\max _{G}\left[(1-t) \sum_{i=1}^{n} L_{i}+\sum_{i=1}^{n} H_{i}\left(g_{i}\right)\right]
$$

s.t. constraint (1),

$$
\begin{gathered}
G=\sum_{j=1}^{n} c_{j} g_{j} \\
c_{i} g_{i}=\alpha_{i} G \text { for } i=1 . . n .
\end{gathered}
$$

Notice that the problem is very similar to the first-best allocation problem (3). The difference is that the federal government decides on the total amount of the public good (vs. the individual public good levels) with the additional constraints on the distribution of this amount across the regions according to the fixed sharing rule.

Following our usual substitution of $t$ as well as $g_{i}$ into the utility function, we derive the following first-order conditions:

$$
\sum_{i=1}^{n} \frac{\alpha_{i}}{c_{i}} \frac{d H_{i}\left(g_{i}^{S R}\right)}{d g_{i}}=1
$$

with $g_{i}=\frac{\alpha_{i} G}{c_{i}}$ for $i=1 . . n$. SR refers to the fixed sharing rule allocation.

There are several conclusions we can draw from expression (9). First, notice that this condition can be rewritten as:

$$
\sum_{i=1}^{n} \frac{\alpha_{i}}{c_{i}}\left[\frac{d H_{i}\left(g_{i}^{S R}\right)}{d g_{i}}-c_{i}\right]=0 .
$$

Since $\alpha_{i} \in(0,1)$, some terms in the square brackets should be non-positive while the other ones should be non-negative. Thus, for some regions $\frac{\partial H_{i}\left(g_{i}^{S R}\right)}{\partial g_{i}} \leq c_{i}$ and for some others the opposite inequality holds. This means that there is, compared to the first best, overprovision in some regions and underprovision in other regions.

Second, we may expect that there is a distribution of regional shares which produces the first best allocation. Moreover, for reasonable shares the loss in terms of utility as compared to the first-best allocation can be relatively small. We provide an illustration of this result and more precise meaning for "reasonable shares" in the case of two regions $i=1,2$ and fixed shares $\alpha \in(0,1)$ and $1-\alpha$. 
From (8) the fixed sharing rule constraint may be expressed as $g_{2}=\frac{c_{1}}{c_{2}} \frac{1-\alpha}{\alpha} g_{1}$. Therefore, the optimal share $\alpha^{*}$ that allows us to obtain the first-best is:

$$
\frac{1-\alpha^{*}}{\alpha^{*}}=\frac{c_{2} g_{2}^{F B}}{c_{1} g_{1}^{F B}}
$$

where $g_{i}^{F B}, i=1,2$ are given by (4). Then, the optimal share for region 1 is:

$$
\alpha^{*}=\frac{1}{1+\frac{c_{2}\left(\frac{\partial H_{2}}{\partial g_{2}}\right)^{-1}\left(c_{2}\right)}{c_{1}\left(\frac{\partial H_{1}}{\partial g_{1}}\right)^{-1}\left(c_{1}\right)}} .
$$

In what follows we obtain an expression of the efficiency loss associated to a sub-optimal choice of $\alpha$. Let us denote by $v(\alpha)$ the value function:

$$
\begin{aligned}
v(\alpha) & =\max _{g_{1}, g_{2}}\left[H_{1}\left(g_{1}\right)-c_{1} g_{1}+H_{2}\left(g_{2}\right)-c_{2} g_{2}\right] \\
\text { s.t. } g_{2} & =\frac{c_{1}}{c_{2}} \frac{1-\alpha}{\alpha} g_{1} .
\end{aligned}
$$

The difference $v\left(\alpha^{*}\right)-v(\alpha)$ corresponds to the loss in utility due to the fixed sharing rule as compared to the first-best allocation.

Function $v(\alpha)$ is continuous, and from the envelope theorem:

$$
v^{\prime}(\alpha)=-\frac{1}{\alpha^{2}} \frac{c_{1}}{c_{2}} g_{1}\left[H_{2}^{\prime}\left(g_{2}\right)-c_{2}\right],
$$

therefore $v^{\prime}\left(\alpha^{*}\right)=0$. One may also check that:

$$
v^{\prime \prime}\left(\alpha^{*}\right)=\left(\frac{1-\alpha^{*}}{\alpha^{*}}\right)^{2}\left(\frac{1}{\left(g_{1}^{F B}\right)^{2} H_{1}^{\prime \prime}\left(g_{1}^{F B}\right)+\left(g_{2}^{F B}\right)^{2} H_{2}^{\prime \prime}\left(g_{2}^{F B}\right)}\right)^{-1} .
$$

Since $v^{\prime \prime}\left(\alpha^{*}\right)<0$, the function $v(\alpha)$ has a maximum at $\alpha^{*}$. Using the Taylor approximation one gets:

$$
v(\alpha)-v\left(\alpha^{*}\right) \approx v^{\prime \prime}\left(\alpha^{*}\right) \frac{\left(\alpha-\alpha^{*}\right)^{2}}{2}
$$

in a neighborhood of $\alpha^{*}$. Therefore, we conclude that for shares that are not too far from the ones restoring the first-best allocation, the utility loss is relatively small.

In section 5 we analyze how the fixed regional shares are determined in a legislative bargaining setting. There we show that the equilibrium fixed shares resulting from the legislative bargaining game are strongly related to the proposal power and population shares. 
The solution generated by the maximization of the unweighted sum of utilities is the most favorable setting to reach the first best with a fixed sharing rule. The other extreme is that one region acts as a dictator and selects the total budget for the public good. This region, denoted by $k$, will maximize its regional welfare under the fixed sharing rule, giving the following solution $g_{k}^{S R(k)}$ :

$$
\frac{d H_{k}\left(g_{k}^{S R(k)}\right)}{d g_{k}}=\frac{L_{k} c_{k}}{L \alpha_{k}} .
$$

Let us assume that the share $\alpha_{k}=\frac{L_{k}}{L}$, i.e., it is proportional to the population size. In the region $k$ the first-best allocation is then restored.

From formula (11) it is easy to calculate the total expenditure $G$ :

$$
G=\frac{c_{k}}{\alpha_{k}} g_{k}^{F B}
$$

as well as the equilibrium allocation for the other regions:

$$
g_{i}^{S R(k)}=\frac{\alpha_{i}}{c_{i}} \frac{c_{k}}{\alpha_{k}} g_{k}^{F B} \text { for } i \neq k .
$$

One can check that, in order to restore the first-best allocation in the other regions, the following condition should be satisfied:

$$
\frac{\alpha_{i}}{\alpha_{k}}=\frac{c_{i} g_{i}^{F B}}{c_{k} g_{k}^{F B}} \text { for } i \neq k,
$$

i.e., for two regions $i$ and $k \neq i$ the ratio of the regional shares should be the same as the ratio of the regional expenditures in the first-best allocation.

We have seen that the fixed regional share allocation has attractive properties when the regional shares are well chosen. The intuition for this result is simple: when a region is in power and can decide on the total expenditure on the public good $G$, even if the public good is paid by all the regions, the fixed share limits the regional benefit of extending the total expenditure on public goods in one's own region. In other words, for every $\alpha$ euro spent in the own region, there is automatically $(1-\alpha)$ euro to be spent in other regions - the fixed 
regional budget share imposes a kind of federal budget constraint to the region making the decision.

\section{Bargaining Stage}

The fixed regional share allocation works well if the shares are reasonably close to the First Best. What can we say about the determination of the regional budget shares? The fixed regional shares can be seen as the outcome of legislative bargaining at federal level.

To show this result, we employ a modified version of the legislative bargaining model of Baron and Ferejohn (1989). In this model $n \geq 3$ symmetric players decide how to divide the budget of size 1 according to a particular voting rule. We consider two cases. The first case is the simple majority rule: it is necessary to have $q$ out of $n$ votes to pass a proposal, where $q \in(n / 2, n)$. The second case is the unanimity rule: $q=n$ and $n \geq 2$. Unanimity may be a requirement if we want to fix the shares for a longer term such as in a constitution.

The players are risk-neutral and only concerned about their own share. Each player $i$ has probability $\left.p_{i} \in\right] 0,1[$ of being selected as a proposer to suggest a distribution among the

players, where $\sum_{i=1}^{n} p_{i}=1$. This player proposes a vector $\mathbf{x} \in \mathbb{R}_{+}^{n}$, with $\sum_{i=1}^{n} x_{i} \leq 1$, where $x_{i}$ is player $i$ 's share of the budget. As soon as the proposal is made, the others vote in favor or against. If a (qualified) majority of the players supports it, the game ends and the budget is distributed according to the proposal, i.e. $x$ is implemented. Otherwise a new proposer is selected and the same procedure is repeated. The players discount the future payoffs by a factor $\delta \in] 0,1[$.

Usually, in the literature, the analysis is restricted to the stationary subgame perfect equilibria (SSPE). The existence result is provided by Banks and Duggan (2000) in a very general setting in which the space of outcomes can be any convex compact set and the utility functions are concave but otherwise unrestricted.

The main predictions of the model are the following: First, there is a property of immediate agreement. Even without discounting, there is a pressure to reach agreement in the first period because of the risk of being excluded afterwards. Second, only minimal winning 
coalitions form in equilibrium, since otherwise it would be a waste of resources for the agenda setter. Third, the proposer receives a disproportionately high share, because he/she always buys the cheapest minimal coalition and pays the minimum amount to its members just enough to secure the acceptance of the proposal.

There is another interesting feature of the equilibrium which will be useful in our analysis. Baron and Ferejohn (1989) show, through the use of examples, that there are possibly multiple equilibria. However, Eraslan (2002) and Eraslan and McLennan (2006), using a quite general setup of the bargaining game, prove uniqueness of the expected payoffs generated by all the game's stationary equilibria.

In the two following sections 5.1 and 5.2 we provide two different explanations for the existence of fixed regional shares in the political bargaining process. In both cases we show how a fixed regional share can arise as an equilibrium and demonstrate properties of these shares. In the first explanation (section 5.1) the fixed shares are considered as decided in a constitutional deal that is agreed upon once and for all. A fixed share can be an equilibrium when the constitution is decided with unanimity or with a qualified majority. In this case the fixed shares correspond to an expected share of public goods over a longer period. The second explanation (section 5.2) does not rely on a once and for all constitutional agreement but assumes that regions agree in advance (without formal vote in a constitutional phase) to implement a proportional sharing rule, whoever becomes agenda setter. There is only a tacit agreement, no explicit constitutional type agreement, on a "punishment" strategy. It is shown that this can also be an equilibrium and gives rise to the regional shares proportional to the bargaining power of the regions. Both approaches explain the fixed shares on the basis of the long term effects in terms of public good allocation, so in both equilibria the discount plays a role.

\subsection{Regional Shares as Expected Payoffs}

In this section we consider the regional shares as fixed in the constitution, and suppose that they are calculated as ex ante expected payoffs obtained from the described bargaining game. Because of the appealing uniqueness property it is valid to do so. 


\subsubsection{Sharing Rule under Unanimity Voting}

In this subsection we assume that it is necessary to have the votes of all $n \geq 2$ players to pass a proposal. Let $y_{i}$ denote player $i$ 's ex ante expected payoff. Then we can write the following system of equations:

$$
y_{i}=p_{i}\left(1-\sum_{\substack{j=1 \\ j \neq i}}^{n} \delta y_{j}\right)+\left(1-p_{i}\right) \delta y_{i} \text { for all } i=1 . . n \text {. }
$$

Thus, the expected payoff $y_{i}$ of player $i$ equals the first term of (13) if he/she is a proposer and the second term of $(13)$ if he/she is not a proposer. With probability $p_{i}$, player $i$ is a proposer, and he/she buys the other players by proposing them their discounted expected payoffs, and he/she takes the remaining. Otherwise, with probability $1-p_{i}$ he/she receives his/her discounted expected payoff.

No-delay property implies:

$$
\sum_{j=1}^{n} y_{j}=1
$$

and therefore, after simplifications the equations (13) become:

$$
y_{i}=p_{i} \text { for all } i=1 . . n \text {. }
$$

Thus, we have proved the following:

Proposition 1 In a unanimity voting system, the expected regional shares equal the probability of being a proposer for any discount factor $\delta \in] 0,1[$.

We obtain that the expected share of player $i$ is equal to his/her probability of being selected as a proposer. If we think of $p_{i}$ as of player $i$ 's proposal power, then we can say that the expected share of the player is proportional to his/her proposal power. Note that this result is independent of the discount factor $\delta$.

If the probability of being a proposer is proportional to the population size of the region, such as in a proportional representation system, the resulting shares $\alpha_{i}$ are also proportional to the population size. 


\subsubsection{Sharing Rule under the Qualified Majority Voting}

In this section we consider the following situation: each player has one vote and $q$ votes are necessary to approve the decision. We take $n=2 l+1, l \geq 1$ and $q \geq l+1$. For the rest of the section we assume that the players have the same discount factor $\delta$, which is close to 1 .

It can be shown ${ }^{3}$ that if the distribution of the proposal power is relatively close to $\left(\frac{1}{n}, \ldots, \frac{1}{n}\right)$ or, more precisely, if $p_{i}-\frac{1}{n}<\frac{q-1}{n(n-(q-1))}$ for all $i=1 \ldots n$, then the vector of

expected payoffs is $\left(\frac{1}{n}, \ldots, \frac{1}{n}\right)$. However, if there are "weak" players (in terms of proposal power) for whom $p_{i}-\frac{1}{n}<\frac{q-1}{n(n-(q-1))}$ and there is a "strong" player $j$ for whom $p_{j}>p_{i}$, then the stronger player gets higher expected payoff as compared to the weaker ones.

This result can be illustrated in the case $n=3$. If probabilities $p_{i}<1 / 2$ for all $i=1,2,3$, everybody receives exactly $1 / 3$. Suppose, there is a "strong" player with the probability of being selected as a proposer larger than $1 / 2$. Without loss of generality we can assume that it is player 3. Then his/her expected payoff is:

$$
y_{3}=\frac{p_{3}}{1+p_{1}+p_{2}},
$$

and each of the two other players gets:

$$
y_{i}=\frac{p_{1}+p_{2}}{1+p_{1}+p_{2}}, i=1,2
$$

In this case one may show that $y_{3}$ is larger than $1 / 3$, and $y_{1}$ and $y_{2}$ are smaller than $1 / 3$.

\subsection{Implementation of Regional Shares through Trigger Strategies}

Up to now we have shown that the fixed regional sharing rule can be explained in terms of the expected payoffs from the legislative bargaining game. Now, we modify our setting slightly. As before, an agenda setter is chosen following a specified probability distribution and the legislators discount future payoffs according to the discount factor $\delta \in] 0,1[$. We suppose the regions agree in advance that, each period, whoever is becoming an agenda setter will propose a proportional distribution of the fixed federal budget, i.e., he/she proposes shares $\left(\alpha_{i}\right)_{i=1 . . n}$

\footnotetext{
${ }^{3}$ see Zaporozhets (2006) for the detailed proof.
} 
In this section we assume that, if at some stage, the chosen agenda setter decides to deviate from the given distribution, the other regions will play a non-cooperative one-stage equilibrium during the following periods. Along the lines of Persson (1998) in such an equilibrium the agenda setter will choose a coalition composed of $q-1$ other regions, and the regions outside this winning coalition get no public good at all, even though they will bear the cost of taxes. Next, the agenda-setter will spend only as much as necessary to keep the members of the winning coalition barely as well off as with the default policy. Lastly, the agenda setter will choose regions that are "cheapest" to buy off, i.e., that value a unit of the public good more than the others.

We are going to investigate a simple case, in which the legislators have the same quasilinear utility $u\left(g_{i}\right)$ from the consumption of the local public good $g_{i}$ :

$$
u\left(g_{i}\right)=(1-t) L_{i}+H\left(g_{i}\right)
$$

where $L_{i}$ is the labor supply in each region $i$. The benefit function $H\left(g_{i}\right)$ is identical for all regions, and as before, we assume that:

$$
H(0)=0, H^{\prime}\left(g_{i}\right)>0 \text { and } H^{\prime \prime}\left(g_{i}\right)<0, i=1 . . n .
$$

Tax $t$ is determined by the federal budget constraint:

$$
t L=\sum_{i=1}^{n} c_{i} g_{i},
$$

where $L=\sum_{i=1}^{n} L_{i}$ and $c_{i}$ is the unit cost of public good provision, and, for simplicity, it is taken to be 1. Therefore, the tax level is just

$$
t=\frac{g}{L}
$$

where $g=\sum_{i=1}^{n} g_{i}$ is the size of the federal funds to be distributed.

In a one-period bargaining game a specified agenda setter $i$ chooses coalition $M^{i}$ of size $q-1$ and offers each of the coalition member as much as is necessary to restore his/her utility under the default outcome with $g_{j}=t=0$ for all $j \in M^{i}$, i.e., 


$$
u\left(g_{j}\right)=L_{j} \text { for each } j \in M^{i} .
$$

Thus, the level of public good each member of the coalition $M^{i}$ gets is defined as:

$$
H\left(g_{j}\right)=\frac{L_{j}}{L} g \text { for any } j \in M^{i} .
$$

Note that coalition $M^{i}$ will contain regions with the smallest $L_{j}$.

We denote by $m_{i}$, the total amount of public good distributed to the members of $M^{i}$, i.e.,

$$
m_{i}=\sum_{i \in M^{i}} H^{-1}\left(\frac{L_{i}}{L} g\right) .
$$

The agenda setter gets $g-m_{i}$. We assume that $g>m_{i}$ for any agenda setter $i$.

The non-members do not get any public good at all, however they bear the costs:

$$
u\left(g_{j}\right)=(1-t) L_{j}=L_{j}-g \frac{L_{j}}{L} \text { for any } j \notin M^{i} .
$$

We would like to identify the conditions under which the deviation is not sustainable. If at some stage of the game, legislator $i$ is chosen to be a proposer and he/she decides to deviate, his/her expected payoff would be:

$$
\begin{aligned}
& {\left[L_{i}-g \frac{L_{i}}{L}+H\left(g-m_{i}\right)\right]+} \\
& \sum_{t=1}^{\infty} \delta^{t}\left[p_{i}\left(L_{i}-g \frac{L_{i}}{L}+H\left(g-m_{i}\right)\right)+\left(1-p_{i}\right)\left(L_{i}-g \frac{L_{i}}{L}\right)\right] .
\end{aligned}
$$

The first term is the maximum the legislator could get by deviating, and the second term reflects the infinite punishment stage: in the following periods the legislator can receive the amount $g-m_{i}$ of public good only if he/she is chosen as a proposer and, if not, he/she simply bears the cost.

Expected payoff (15) should be compared with his/her expected payoff under the assumption that he/she cooperates through all the periods, i.e., he/she gets share $\alpha_{i}$ : 


$$
\sum_{t=0}^{\infty} \delta^{t}\left[L_{i}-g \frac{L_{i}}{L}+H\left(\alpha_{i} g\right)\right] .
$$

That is, we examine under which conditions expected payoff (16) is at least as high as (15), i.e., the following inequality holds true:

$$
\sum_{t=0}^{\infty} \delta^{t} H\left(\alpha_{i} g\right) \geq H\left(g-m_{i}\right)+\sum_{t=1}^{\infty} \delta^{t} p_{i} H\left(g-m_{i}\right)
$$

or

$$
\frac{1}{1-\delta} H\left(\alpha_{i} g\right) \geq H\left(g-m_{i}\right)+\frac{\delta}{1-\delta} p_{i} H\left(g-m_{i}\right)
$$

Multiplying both sides of the inequality by $(1-\delta)$ and rearranging the terms we get:

$$
\delta \geq \bar{\delta} \equiv \frac{H\left(g-m_{i}\right)-H\left(\alpha_{i} g\right)}{\left(1-p_{i}\right) H\left(g-m_{i}\right)} .
$$

Thus, the deviation is not sustainable if and only if $\bar{\delta}$ is smaller than 1 .

One can check that $\bar{\delta}<1$ if and only if:

$$
H\left(g-m_{i}\right)<\frac{1}{p_{i}} H\left(\alpha_{i} g\right) .
$$

Since the benefit function $H$ is concave

$$
H\left(\alpha_{i} g\right) \geq \alpha_{i} H(g)
$$

Assuming that $\alpha_{i}=p_{i}$ we get that:

$$
\frac{1}{p_{i}} H\left(\alpha_{i} g\right) \geq H(g)>H\left(g-m_{i}\right),
$$

and therefore (18) is satisfied. Thus, we showed that under the additional assumption $\alpha_{i}=p_{i}$ there exists a threshold $\bar{\delta}<1$ such that for $\delta \geq \bar{\delta}$ the fixed sharing rule can be implemented. 


\section{Numerical Illustration for Railway Investments in Belgium}

Belgium is a federal country that consists of three regions: Brussels (capital and centrally located), Flanders and Walloon region. Historically a tradition developed that only railway investment plans satisfying the rule "60\% (for Flanders) and $40 \%$ (for Wallonia)" can be accepted by the federal parliament. These budget shares are effectively close to the share of representatives (and population) of the two regions, and illustrate therefore our fixed share equilibrium $^{4}$. We calibrate a small numerical example to illustrate the effect of the fixed sharing rule.

\subsection{Calibration of the Model}

Let us denote by $f$ and $w$ the Flanders and Walloon regions respectively. We assume that the observed equilibrium is a fixed share equilibrium with fixed shares $60 \%$ for Flanders and $40 \%$ for Wallonia.

We use the following specification:

$$
H_{i}\left(g_{i}\right)=2 \lambda_{i} \sqrt{g_{i}}, i=f, w
$$

where $\lambda_{i}$ is a calibration parameter for the benefit function, and assume average cost per unit of rail investment $c_{i}$ in each region $i=f, w$. The rail geography of Belgium is such that most commuting flows go from Wallonia and Flanders to Brussels but almost no commuting flows between Flanders and Wallonia.

We can therefore neglect regional spillovers between Flanders and Wallonia. The rail investments in Brussels are considered to benefit the whole federation and are kept outside the fixed share allocation mechanism and are not discussed here.

For the calibration of the model we need two assumptions. First, it is often claimed that

\footnotetext{
${ }^{4}$ Of course, every political system has its own particularities and describing the Belgian political system would be a paper itself.
} 
the construction cost is higher in the more hilly Wallonia than in Flanders. We normalize the Walloon construction $\operatorname{cost} c_{w}$ to one and assume that $c_{f}=0.85$. Second, we assume that the density of the railway network ${ }^{5}$ is 1.54 times higher in Flanders than in Wallonia. We use this observation to assume that the benefit scale parameter $\lambda_{i}$ is larger for Flanders:

$$
\lambda_{f}=1.54 \lambda_{w}
$$

From "Nationaal Instituut voor de Statistiek" (NIS) 2001 we know that

$$
L_{f}=5,952,552 \text { and } L_{w}=3,346,457 .
$$

In 2001, Belgium invested 532.6 million euro in railway infrastructure, so we have:

$$
G=c_{w} g_{w}^{S R}+c_{f} g_{f}^{S R}=532.6 \text { million euro. }
$$

We know that the share of Flanders is $\alpha=0.6$. From (19) and the fact that $c_{f} g_{f}=\alpha G$ and $c_{w f} g_{w}=(1-\alpha) G$ we can easily calculate the total investment levels for the fixed sharing rule in each region:

$$
\begin{aligned}
& g_{f}^{S R}=5.326 \times 10^{8} * 0.6 / 0.85=376 \text { million euro and } \\
& g_{w}^{S R}=5.326 \times 10^{8} * 0.4=213 \text { million euro }
\end{aligned}
$$

We assumed that the observed equilibrium satisfies (9):

$$
\frac{\alpha}{c_{f}} \frac{\lambda_{f}}{\sqrt{g_{f}}}+\frac{1-\alpha}{c_{w}} \frac{\lambda_{w}}{\sqrt{g_{w}}}=1
$$

From this condition it is easy to find $\lambda_{w}$ :

$$
\left(\frac{1.54 \alpha}{0.85 \sqrt{g_{f}}}+\frac{1-\alpha}{\sqrt{g_{w}}}\right) \lambda_{w}=1
$$

and therefore,

$$
\lambda_{w}=\left(\frac{1.54 * 0.6}{0.8 * \sqrt{3.76} \times 10^{4}}+\frac{0.4}{\sqrt{2.13} \times 10^{4}}\right)^{-1}=11981 .
$$

\footnotetext{
${ }^{5}$ The density is the number of people per kilometer of rail. In Flanders the density is 5952552/1848.7 = 3219.9 and in Wallonia it is $3346457 / 1605.3=2084.6$.
} 


\subsection{Scenarios}

Taking all parameters into consideration, we are able to compute alternative equilibria. The first-best allocation becomes:

$$
g_{f}^{F B}=\left(\frac{11981 * 1.54}{0.85}\right)^{2}=471 \text { million euro, }
$$

and

$$
g_{w}^{F B}=\left(\frac{\lambda_{w}}{c_{w}}\right)^{2}=(11981)^{2}=144 \text { million euro. }
$$

Thus, in the first-best allocation Wallonia gets $23 \%$ and $77 \%$ goes to Flanders.

From (10) the optimal share $\alpha^{*}$ that could generate the first best in this case would be:

$$
\alpha^{*}=\frac{1}{1+\frac{c_{w}}{c_{f}} \frac{g_{w}^{F B}}{g_{f}^{F B}}}=\frac{1}{1+\frac{144}{0.85 * 471}}=0.735 .
$$

The difference $\left(\alpha^{*}-\alpha\right)$ is 0.135 .

One can notice that $L_{f} / L=0.64$ which is rather close to $\alpha=0.6$.

The numerical results for alternative equilibria are presented in Table 1, where utility levels are given in millions of euro. The federal utility (the first column) is defined as the simple sum of the regional utilities.

Table 1: Numerical Example.

\begin{tabular}{l|llllll} 
Allocations & $\begin{array}{l}\text { Utility } \\
(\text { fed })\end{array}$ & $\begin{array}{l}\text { Utility } \\
(\mathbf{F})\end{array}$ & $\begin{array}{l}\text { Utility } \\
(\mathbf{W})\end{array}$ & $\begin{array}{l}\text { Invest- } \\
\text { ment (F) }\end{array}$ & $\begin{array}{l}\text { Invest- } \\
\text { ment (W) }\end{array}$ & Efficiency \\
\hline \hline $\mathrm{FB}$ & 553 & 459 & 95 & $100 \%$ & $100 \%$ & $100 \%$ \\
$\mathrm{CP}$ & 157 & 46 & 111 & $200 \%$ & $630 \%$ & $28 \%$ \\
$\mathrm{SR}$ & 542 & 381 & 161 & $80 \%$ & $148 \%$ & $98 \%$ \\
$\mathrm{SR}(\mathrm{f})$ & 540 & 381 & 159 & $88 \%$ & $163 \%$ & $98 \%$ \\
$\mathrm{SR}(\mathrm{w})$ & 538 & 375 & 163 & $66 \%$ & $123 \%$ & $97 \%$
\end{tabular}

We see that the common pool (CP) equilibrium indeed performs very poorly, with an efficiency of $29 \%$ of the first-best (FB) equilibrium. The fixed regional sharing rule (SR) 
with different specifications produces relatively good results. SR represents the equilibrium obtained when the federal government chooses the total level of public goods that maximizes the sum of regional utilities but respects the regional shares (see (9)). This could be seen as the outcome of a coalition government. Equilibria $\mathrm{SR}(\mathrm{f})$ and $\mathrm{SR}(\mathrm{w})$ correspond to the case where the same regional shares are used but where the total supply of public goods maximizes the welfare function of the regions $\mathrm{f}$ or $\mathrm{w}$. The result is that the three fixed share equilibria (SR, $\mathrm{SR}(\mathrm{f})$ and $\mathrm{SR}(\mathrm{w})$ ) all perform strikingly much better in efficiency terms than the common pool equilibrium. The main explanation for this result is that, in the fixed sharing equilibrium, the proposer is limited in exploiting his/her agenda setting power: whatever extra supply of public goods he/she wants his/her region implies that he/she will have to also supply public goods to the other regions.

To check that our results do not directly follow from a particular choice of parameters we provide a sensitivity test. We change the power in the utility function from 0.5 to 0.25 and 0.75 , respectively. The performed calculations are presented in the following Table 2 .

\begin{tabular}{|c|c|c|c|c|c|c|}
\hline \multirow[b]{2}{*}{ Allocations } & \multicolumn{3}{|c|}{ power $\mathbf{0 . 2 5}$} & \multicolumn{3}{|c|}{ power $\mathbf{0 . 7 5}$} \\
\hline & $\begin{array}{l}\text { Invest } \\
(\mathrm{F})\end{array}$ & $\begin{array}{l}\text { Invest } \\
(\mathbf{W})\end{array}$ & Efficiency & $\begin{array}{l}\text { Invest } \\
\text { (F) }\end{array}$ & $\begin{array}{l}\text { Invest } \\
(\mathbf{W})\end{array}$ & Efficiency \\
\hline FB & $100 \%$ & $100 \%$ & $100 \%$ & $100 \%$ & $100 \%$ & $100 \%$ \\
\hline $\mathrm{CP}$ & $158 \%$ & $341 \%$ & $87 \%$ & $398 \%$ & $3981 \%$ & $24 \%$ \\
\hline SR & $92 \%$ & $115 \%$ & $99.9 \%$ & $53 \%$ & $325 \%$ & $98 \%$ \\
\hline $\mathrm{SR}(\mathrm{f})$ & $92 \%$ & $115 \%$ & $99.9 \%$ & $77 \%$ & $471 \%$ & $98 \%$ \\
\hline $\mathrm{SR}(\mathrm{w})$ & $92 \%$ & $115 \%$ & $99.9 \%$ & $25 \%$ & $153 \%$ & $97 \%$ \\
\hline
\end{tabular}

As one can see for the steeper utility function, performance of the different sharing rules improves. We also tested that equal regional costs $c_{f}=c_{w}$ do not change the main conclusions. 


\section{Conclusion}

In this paper, we analyzed the properties of fixed sharing rules for regional public expenditures. The sharing rules are sometimes explicitly imposed in some federal countries and sometimes implicitly imposed in that they serve as check for a political acceptable allocation of expenditures over regions. In this paper we show two important characteristics of the fixed sharing rules. First, the fixed sharing rule acts as a strong budget constraint for any representative that wants to favor his own region. Indeed, for every euro spent in his own region he is forced to spend $\mathrm{X}$ euro in the other region and he has to pay for these expenditures too. This hidden budget constraint acts as a powerful break for common pool type of public expenditure behavior. The second important characteristic is that the sharing rule itself can be an equilibrium of federal bargaining at the constitutional level or can be an equilibrium in trigger strategies where other regions punish the deviating region. The shares are therefore closely related to proposal and voting power at the level of federation. In some cases this implies that relative population and number of representatives of districts will be determining the sharing rules. Using these two characteristics we show that the fixed sharing rule allocation performs somewhere between the first best and the common pool allocation.

If the public expenditure needs are closely correlated to the population and the per-unit cost is not very different across regions, then the expenditure shares will match the political power and the allocation will be relatively efficient.

We used two types of simplifications to examine the properties of the fixed sharing rule allocation. The first type relates to the production and consumption of the public good. We neglected spillovers to other regions and economics of scale. Our model can be generalized in this respect, all we need is that these elements were known and integrated in the federal bargaining phase. The second major simplification is that we used homogeneous regions. This implies that we neglected differences in preferences that could form other coalitions across regions. This has been discussed by Besley and Coate (2013). For instance, one could imagine that intensive public transport users form a nationwide coalition to spend more on public transport in the whole country and that sharing mechanisms different from the 
regional voting shares start to play a role.

\section{References}

[1] Banks J. S. and J. Duggan, 2000. "A Bargaining Model of Collective Choice", American Political Science Review 94(1), 73-88.

[2] Baron, D. P. and J. A. Ferejohn, 1989. "Bargaining in Legislatures", American Political Science Review 83, 1181-1206.

[3] Baron, D.P., 1991. "A Spatial Bargaining Theory of Government Formation in Parliamentary Systems", American Political Science Review 85(1), 137-164.

[4] Beach, H.L, Hammer J., Hewitt J. J., Kaufman, E., Oppenheimer, J. A. and A. T. Wolf, 2000. Transboundary Freshwater Dispute Resolution: Theory, Practice, and Annotated References. United University Press, Tokyo, Japan.

[5] Besley, T. and S. Coate, 2003. "Centralized versus Decentralized Provision of Local Public Goods: A Political Economy Approach", Journal of Public Economics 87, 26112637.

[6] Dixit, A., Grossman, G.M. and R. Helpman, 1997. "Common Agency and Coordination: General Theory and Application to Government Policy Making", Journal of Political Economy, 105(4), 725-769.

[7] Bristow, G., 2001. Bypassing Barnett: The Comprehensive Spending Review and Public Expenditure in Wales, Economic Affairs, 21(3) 44-47.

[8] Eraslan, H., 2002. "Uniqueness of Stationary Equilibrium Payoffs in the Baron-Ferejohn Model", Journal of Economic Theory 103, 11-30.

[9] Eraslan, H., A. McLennan, 2006. "Uniqueness of Stationary Equilibrium Payoffs in Coalitional Bargaining", forthcoming in Journal of Economic Theory. 
[10] Knight, B., 2002. "Endogenous Federal Grants and Crowd-out of State Government Spending: Theory and Evidence from the Federal Highway Aid Program", American Economic Review 92(1), 71-92.

[11] Knight, B., 2004. "Parochial Interests and the Centralized Provision of Local Public Goods: Evidence from Congressional Voting on Transportation Projects", Journal of Public Economics 88, 845-866.

[12] Knight, B., 2005. "Estimating the Value of Proposal Power", American Economic Review 95(5), 1639-1652.

[13] Montero, M., 2006. "Noncooperative Foundations of the Nucleolus in Majority Games", Games and Economic Behavior, 54(2) 380-397.

[14] Montero, M., 2007. "Inequity Aversion May Increase Inequity", The Economic Journal, 117 192-204.

[15] Moulin, H., 2002. "Axiomatic Cost and Surplus Sharing" in A.K. Sen and K. Suzumura,eds., Handbook of Social Choice and Welfare, vol. 1, ch. 6, pp. 289-357.

[16] Persson, T., 1998. "Economic Policy and Special Interest Politics", The Economic Journal, 108(447), 310-327.

[17] Snyder, J.M., Ting, M. M. and S. Ansolabehere, 2005. "Legislative Bargaining under Weighted Voting", American Economic Review 95(4), 981-1004.

[18] Tullock, G., 1959. "Some problems of majority voting", Journal of Political Economy $67,571-579$.

[19] Weingast, B.R., Shepsle K.A. and C. Johnsen, 1981. "The Political Economy of Benefits and Costs: A Neoclassical Approach to Distributive Politics", Journal of Political Economy 89(4), 642-664.

[20] Young H.P., 1994. "Cost Allocation", Chapter 34 in R.J. Aumann and S. Hart, eds., Handbook of Game Theory, vol. 2, pp. 1193-1235. 
[21] Young H.P., Okada, N. and T. Hashimoto, 1982. "Cost Allocation in Water Resources Development", Water Resources Research 18(3), 463-475.

[22] Zaporozhets, V. "Essays on Political Economy and Social Choice", Ph.D. Thesis, University of Toulouse, December 2006. 